\title{
We are Still Learning from Death: After CPR, Balloon Expanding Valve (Intuity Aortic Valve) Revealed to be in Position
}

\author{
Ahmed Ghazy*1, Irem Karliova ${ }^{2}$ and Ch-F Vahl ${ }^{1}$ \\ ${ }^{1}$ Department of Cardiac-Thoracic and Vascular surgery of the Mainz University, Mainz University, Johannes Gutenberg \\ University, Germany \\ ${ }^{2}$ Department of Cardiac-Thoracic and Vascular surgery of the Saarland University, Saarland University, Germany
}

*Corresponding author: Ahmed Ghazy, Department of Cardiac-Thoracic and Vascular surgery of the Mainz University, Mainz University, Johannes Gutenberg University, Germany

\begin{tabular}{|c|c|}
\hline ARTICLE INFO & ABSTRACT \\
\hline Received: 蔧 February 26, 2021 & $\begin{array}{l}\text { Citation: Ahmed Ghazy, Irem Karliova, Ch-F Vahl. We are Still Learning from Death: After } \\
\text { CPR. Balloon Expanding Valve (Intuity Aortic Valve) Revealed to be in Position. Biomed }\end{array}$ \\
\hline Published: 幽 March 11, 2021 & Sci \& Tech Res 34(3)-2021. BJSTR. MS.ID.005562. \\
\hline
\end{tabular}

\section{Introduction}

Patients with high predicated risk undergo TAVI as an alternative treatment to surgical valve replacement. Among several possible complications it has been documented a TAVI implanted valve failure after CPR. Recently rises the AVR using a balloon expandable valve system (INTUITY Elite) as an alternative procedure for similar group of high risk patients. We present a case of Aortic valve replacement (AVR) with a balloon expandable valve system (INTUITY Elite) which showed a very satisfactory alternative without Valve dysfunction after CPR.

\section{Case Report}

In August 2015, a 76 year old male was admitted to our hospital with sever Dyspnoea. The patient suffered from coronary heart disease which was successfully with PTCA and a Stent implantation in Left anterior descending coronary artery (LAD) with currently a long-term Stent patency without any new intervention's indication. The echocardiographic findings included severe aortic valve stenosis, aortic valve regurgitation and sever Mitral valve regurge. The patient was referred to our department for the surgical management. The decision was made for an urgent procedure that included aortic valve replacement using a balloon expanding valve system (INTUITY Elite) and Mitral valve annuloplasty using (CE- Physio II Ring). After a complication-free operation and postoperative course the patient was transferred to intermediate care unit in very stable status in the 1 st post-op day. At the same night, because of a phase of ventricular tachycardia a Cardio pulmonary resuscitation was begun for 15 minutes. To exclude neurological deficits a Brain-CT was done, which didn't show any intracranial hemorrhage, ischemia or skull-fracture. A ThoracicCT was done which revealed a good positioned aortic valve, Mitral ring and irrelevant pericardial effusion (Figure 1). On the $4^{\text {th }}$ postop day, the patient showed a positive Babinski-reflex bilaterally. A Brain CT showed a fresh occipital infarct bilaterally, cerebrally bilaterally and pontin. On $15^{\text {th }}$ post-op day the patient passed away. 

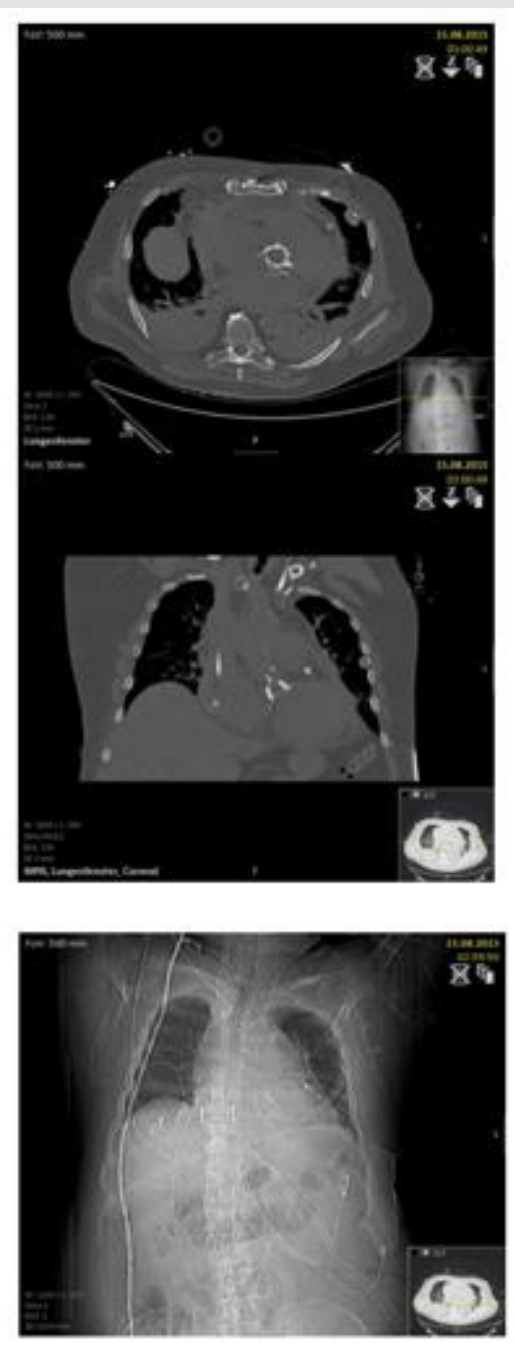

Figure 1: CT Picture showing the balloon expanding valve system in position after cardiopulmonary resuscitation.

\section{ISSN: 2574-1241}

DOI: 10.26717/BJSTR.2021.34.005562

Ahmed Ghazy. Biomed J Sci \& Tech Res

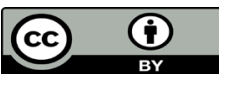

This work is licensed under Creative Commons Attribution 4.0 License

Submission Link: https://biomedres.us/submit-manuscript.php

\section{Conclusion}

After the cardiopulmonary resuscitation period of 15 minutes; the aortic valve prosthesis (INTUITY Elite) was appeared to be in a position in comparison to the documented dislocation or distortion of TAVI prosthesis after CPR [1,2]. According to our experience in the period from 2012 - 2014 we haven't documented any case of valve dislocation from those who underwent through AVR using balloon expanded valve system (INTUITY Elite).

\section{References}

1. Kim EK, Choi SH, Song PS, Park SJ (2014) Valve Prosthesis Distortion After Cardiac Compression in a Patient Who Underwent Transcatheter Aortic Valve Implantation (TAVI). Catheterization and Cardiovascular Interventions 83(3): E165-E167.

2. N Schnelle, U Hink, M Wohlhöfer, D Ister, A Jabs, et al. (2012) Postoperative occlusion of a transapical implanted valve due to mechanical CPR. Thorac Cardiovasc Surg p. 27.

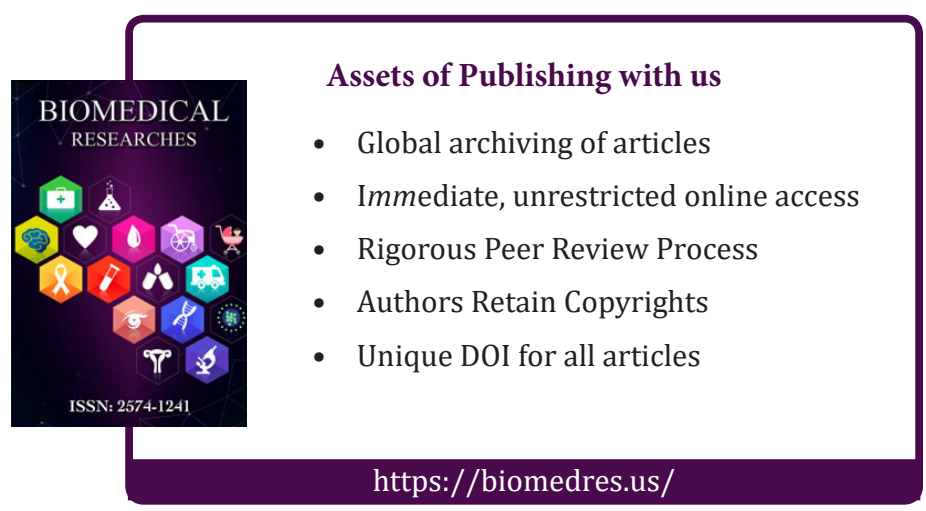

